\title{
Downregulation of survivin expression and elevation of caspase-3 activity involved in pitavastatin-induced HepG 2 cell apoptosis
}

\author{
JUYONG WANG, ZHENYE XU and MING ZHANG \\ Tumor Research Institute, Shanghai Academy of Traditional Chinese Medicine, \\ 725 Southern Wan Ping Road, Box 69, Shanghai 200032, P.R. China
}

Received January 24, 2007; Accepted April 5, 2007

\begin{abstract}
The aim of the present study was to research the apoptosis of human hepatocellular carcinoma cell line HepG 2 induced by pitavastatin. HepG 2 cells were treated with increasing doses of pitavastatin or with mevalonic acid for $48 \mathrm{~h}$. The proliferation of cells was detected with WST-8. The morphology of the nucleus was observed under a microscope by Hoechst 33258 staining. The apoptosis peaks were examined by flow cytometry. The expression of survivin mRNA was examined with RT-PCR. The caspase-3 activity was detected with caspase- 3 colorimetric protease assay. We found that growth inhibitory effects were observed for treatment with pitavastatin at 10-50 $\mu \mathrm{M}$. Pitavastatin at $10 \mu \mathrm{M}$ induced granular apoptotic bodies of HepG 2 cells. Furthermore, pitavastatin at $10 \mu \mathrm{M}$ increased the appearance of sub-G1 population of HepG 2 cells. Finally, pitavastatin at $10 \mu \mathrm{M}$ downregulated the expression of survivin mRNA and upregulated the caspase- 3 activity, which was clearly related to the HMG-CoA reductase activity. These results suggest that pitavastatin at $10 \mu \mathrm{M}$ induces apoptosis of HepG 2 cells, which is associated with the decreased expression of survivin mRNA and increased caspase- 3 activity of HepG 2 cells.
\end{abstract}

\section{Introduction}

Hepatocellular carcinoma (HCC) is one of the most common cancer-related causes of death worldwide. In light of the very poor 5-year survival, new therapeutic approaches are mandatory (1). The 3-Hydroxy-3-methyl-glutaryl-CoA (HMG$\mathrm{CoA}$ ) reductase inhibitors, statins, are widely used with cholesterol-lowering drugs. The liver is the primary target organ for these drugs, and they inhibit the rate-limiting step

Correspondence to: Dr Juyong Wang, Tumor Research Institute, Shanghai Academy of Traditional Chinese Medicine, 725 Southern Wan Ping Road, Box 69, Shanghai 200032, P.R. China

E-mail: wangjuyong1@126.com

Key words: apoptosis, survivin, caspase-3, hepatocellular carcinoma cell, pitavastatin in cholesterol synthesis (2). Interestingly, recent studies have emphasized that some of the non-lipid-related effects of statins present potential benefits, such as anti-cancer effects in vitro. It has also been suggested that they increase survival time for patients with advanced hepatocellular carcinoma in combination with 5-fluorouracil (3).

Survivin is one of the apoptosis inhibitors and plays a key role in the mechanism of anti-apoptosis of tumors (4). If the activity of it is suppressed, tumor cells can undergo apoptosis and stop growing (5). In addition, survivin inhibits various modulation elements of cell apoptosis and exerts their action through the caspase enzyme system. Among them, caspase-3 is probably the one that so far best correlates with apoptosis (6). Furthermore, caspase-3 expression was detected in several human malignancies such as non-small cell lung carcinoma and gastric cancer $(7,8)$. Statins have been proposed as promising adjunctive anti-cancer agents to treat $\mathrm{HCC}$, but their mode of action is still poorly characterized (9). Pitavastatin is a novel highly potent inhibitor of $\mathrm{HMG}-\mathrm{CoA}$ reductase, the ratelimiting enzyme in cholesterol biosynthesis (10). The mechanisms of the anti-cancer effect by pitavastatin have been poorly investigated in hepatocellular carcinoma cells. Therefore, the purpose of the present study was to examine the effect of pitavastatin treatment on the apoptosis of hepatocellular carcinoma cells (HepG 2). Here, we showed that pitavastatin induces apoptosis in HepG 2 cells, which is associated with the decreased expression of survivin mRNA and increased caspase- 3 activity of HepG 2 cells .

\section{Materials and methods}

Reagents. Pitavastatin (Livalo $\left.{ }^{\circledR}, \mathrm{NK}-104\right)$ was kindly provided by Kowa Co., Ltd. (Nagoya, Japan) and Nissan Chemical Industries, Ltd. (Tokyo, Japan). Dimethyl sulfoxide (DMSO) was purchased from Wako Pure Chemical Industries (Osaka, Japan). Mevalonic acid (MEV) and Hoechst 33258 were purchased from Sigma (St. Louis, MO, USA).

Cell culture. The hepatocellular carcinoma cell line HepG 2 was originally obtained from the American Type Culture Collection (ATCC) and maintained in DMEM medium (Sigma) containing 10\% fetal bovine serum (FBS). The cells 


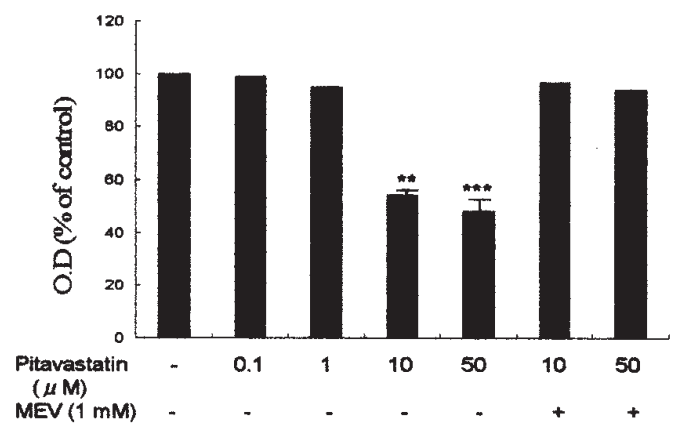

Figure 1. Growth inhibition of pitavastatin in HepG 2 cells. Cells were treated with different concentrations of pitavastatin and/or MEV $(1 \mathrm{mM})$ for $48 \mathrm{~h}$. The cell growth was determined using a WST-8 colorimetric assay. The results are expressed as percentages of cell growth relative to untreated control cells. The data represent the means $\pm \mathrm{SD}(\mathrm{n}=3) ;{ }^{* *} \mathrm{p}<0.01,{ }^{* * *} \mathrm{p}<0.001$ vs. control.

were maintained at $37^{\circ} \mathrm{C}$ in $5 \% \mathrm{CO}_{2}$. For experiments, the cells were seeded in 6-well culture plates and grown in complete medium to $90 \%$ confluence. Then, the cells were washed with phosphate-buffered saline (PBS) and incubated for $48 \mathrm{~h}$ at $37^{\circ} \mathrm{C}$ in $2 \mathrm{ml}$ of serum-free medium containing pitavastatin or vehicle, in the presence or absence of MEV.

WST-8 assay. The cell proliferation was evaluated using a WST-8 [2-(2-methoxy-4-nitrophenyl)-3-(4-nitrophenyl)-5-(2, 4-disulfophenyl)-2H-tetrazolium, monosodium salt] colorimetric assay. HepG 2 cells $\left(1 \times 10^{4}\right.$ cells/well) were seeded into 96-well plates in $100 \mu 1$ of culture medium overnight, and then treated with various concentrations of pitavastatin for $48 \mathrm{~h}$. Next, $10 \mu \mathrm{l}$ of WST-8 reagent solution (Cell Counting kit, Dojindo Laboratories, Japan) was added and incubated for $2 \mathrm{~h}$. Cell viability was determined according to the manufacturer's instructions.

Hoechst 33258 staining. To observe nucleus changes occurring during apoptosis, the chromation-specific dye Hoechst 33258 was used (11). Cultures were fixed for $5 \mathrm{~min}$ with $4 \%$ formaldehyde in PBS at $37^{\circ} \mathrm{C}$ and then permeabilized by treatment with a mixture of ethanol/acetic acid (3:1) for $10 \mathrm{~min}$ at $25^{\circ} \mathrm{C}$. After being washed with PBS, the cells were stained with $1 \mu \mathrm{g} / \mathrm{ml}$ Hoechst 33258 in PBS for $10 \mathrm{~min}$ at room temperature and then washed again. Apoptosis was determined morphologically after staining the cells with Hoechst 33258 using fluorescence microscopy.

Flow cytometric analysis. Cells were harvested by trypsinization, washed twice with ice-cold PBS, re-suspended in ice-cold PBS and fixed with $70 \%$ ethanol. When ready to stain with propidium iodide (PI), the cells were centrifuged. After the ethanol was removed, the cells were washed once in PBS. The cell pellets were then re-suspended in $1 \mathrm{ml}$ of PI/Triton X-100 staining solution ( $0.1 \%$ Triton $\mathrm{X}-100$ in PBS, $0.2 \mathrm{mg} / \mathrm{ml} \mathrm{RNase} \mathrm{A} \mathrm{and} 10 \mu \mathrm{g} / \mathrm{ml}$ propidium iodide) and incubated for at least $30 \mathrm{~min}$ at room temperature. The stained cells were analyzed using a FACScan flow cytometer in combination with BD Lysis II software (Becton Dickinson).

$R T-P C R$ for the detection of survivin mRNA expression. Survivin mRNA expression in HepG 2 cells was determined by
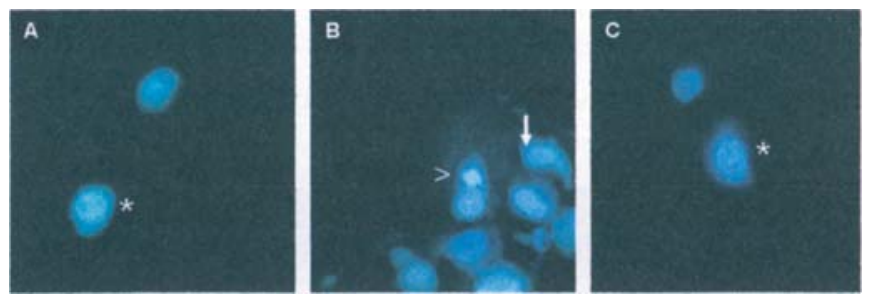

Figure 2. Fluorescence photomicrographs of HepG 2 cells with Hoechst 33258 staining. The assessment of nuclear morphology of the cell was performed after HepG 2 cells were incubated for $48 \mathrm{~h}$ with vehicle (A), with $10 \mu \mathrm{M}$ pitavastatin (B) or with $10 \mu \mathrm{M}$ pitavastatin and $\mathrm{MEV}$ (C) respectively. $(*)$ Normal nuclear structure; $(\rightarrow)$ cytoplasmic change; $(>)$ nuclear fragmentation (Hoechst 33258x400).

RT-PCR analysis. To prepare the samples for the analysis, we isolated the total RNA from HepG 2 cells using Isogen (Nippon Gene, Toyama, Japan) according to the manufacturer's instructions. The primers used were survivin sense: 5'-GGA CCACCGCATCTCTACAT-3', antisense: 5'-GCACTTTCT TCGCAGTTTCC-3' (12); and GAPDH sense: 5'-ACCACA GTCCATGCCATCAC-3', antisense: 5'-TCCACCACCCT GTTGCTG-3'. The reaction parameters of survivin were as follows: $95^{\circ} \mathrm{C}$ for $5 \mathrm{~min}, 94^{\circ} \mathrm{C}$ for $1 \mathrm{~min}, 54^{\circ} \mathrm{C}$ for $1 \mathrm{~min}, 72^{\circ} \mathrm{C}$ for $1 \mathrm{~min}$ for 30 cycles and $72^{\circ} \mathrm{C}$ extension for $10 \mathrm{~min}$. The PCR products were separated in $2 \%$ agarose gels, visualized by staining with ethidium bromide and analyzed with Image 1.62.

Caspase- 3 activity assay. To analyze caspase- 3 activity, HepG 2 cells $\left(1 \times 10^{6}\right.$ cells) were treated with reagents for $48 \mathrm{~h}$. The caspase- 3 activity was measured with a caspase- 3 colorimetric protease assay kit (Medical \& Biological Laboratories Co., Ltd., Japan) according to the manufacturer's instructions.

Statistical analysis. Data are presented as means \pm SD. Statistical analysis was performed with SPSS 10.0 software. $\mathrm{P}<0.05$ was considered statistically significant.

\section{Results}

Growth inhibition of HepG 2 cells by pitavastatin. To elucidate the optimal administration for pitavastatin in HepG 2 cells, the effect of pitavastatin $(0.1-50 \mu \mathrm{M})$ on HepG 2 cell proliferation was examined by the WST- 8 assay. Compared with the control, pitavastatin at 10 and $50 \mu \mathrm{M}$ markedly inhibited proliferation of HepG 2 cells (Fig. 1). The treatment of HepG 2 cells with up to $1 \mu \mathrm{M}$ pitavastatin had no significant effect on cell viability. Growth inhibition by pitavastatin was completely abolished by MEV (1 mM).

Apoptosis in HepG 2 cells induced by pitavastatin. To investigate whether HepG 2 cells underwent apoptosis when they were treated with pitavastatin, the cells were stained with propidium iodide, followed by an examination of the appearance of sub-G1 population using a flow cytometry. After treatment with $10 \mu \mathrm{M}$ of pitavastatin for $48 \mathrm{~h}$, cell death became apparent. As evidenced by the appearance of sub-G1 population, the apoptotic index in HepG 2 cells was $24.3 \%$. Regarding the specificity of the effect of pitavastatin, MEV $(1 \mathrm{mM})$ abolished the induction of apoptosis by pitavastatin 

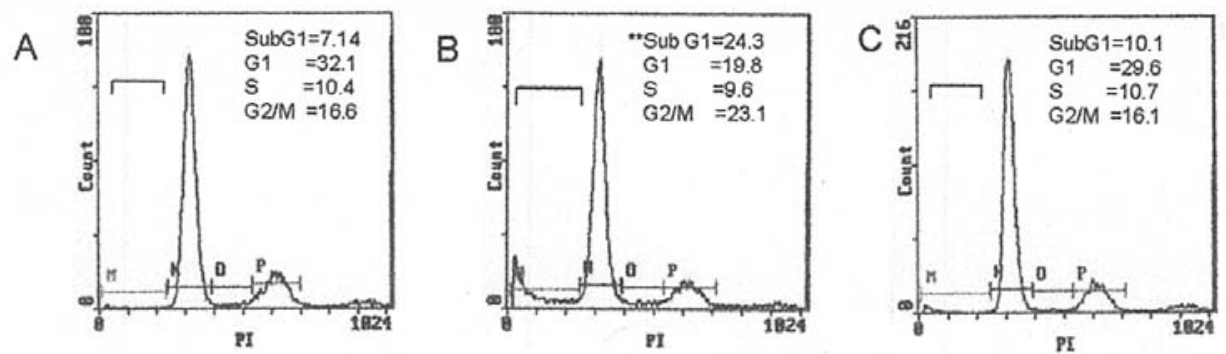

Figure 3. Cell cycle analysis of HepG 2 cells treated with pitavastatin by flow cytometry. Subconfluent monolayers of HepG 2 cells were treated with pitavastatin $(10 \mu \mathrm{M})$ alone, or pitavastatin $(10 \mu \mathrm{M})$ and MEV $(1 \mathrm{mM})$ for $48 \mathrm{~h}$. The cells were fixed with ice-cold $70 \%$ ethanol, treated with RNase A and stained with propidium iodide in the dark. The percentage of non-apoptotic and apoptotic cells within each cell cycle was observed by flow cytometry. The data represent the means $\pm \mathrm{SD}(\mathrm{n}=3) ;{ }^{* *} \mathrm{p}<0.01$ vs. control.

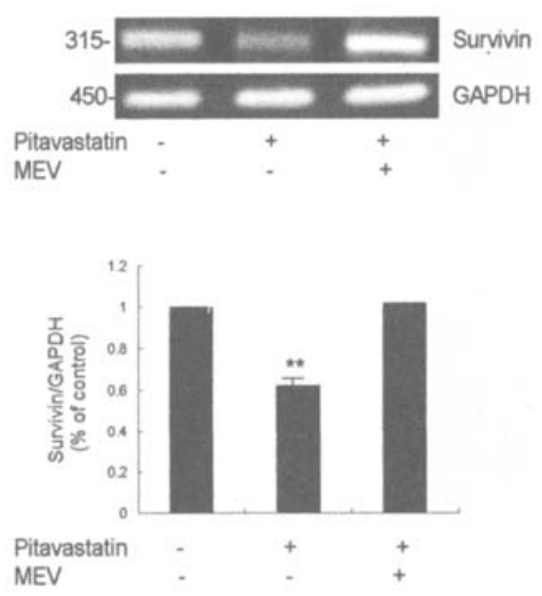

Figure 4. Survivin mRNA expression following treatment with pitavastatin. Subconfluent monolayers of HepG 2 cells were treated with pitavastatin $(10 \mu \mathrm{M})$ alone, or pitavastatin $(10 \mu \mathrm{M})$ and MEV $(1 \mathrm{mM})$ for $48 \mathrm{~h}$. After the treatment, RNA was extracted. Levels of survivin and GAPDH mRNA were examined by RT-PCR. The two top panels show the expression levels of survivin and GAPDH mRNA; the bottom bar graphs shows the expression levels of survivin relative to those of GAPDH. The data represent means \pm $\mathrm{SD}(\mathrm{n}=3) ;{ }^{* *} \mathrm{p}<0.01$ vs. control.

(Fig. 3). Furthermore, we also observed the morphologic changes of the nucleus by Hoechst 33258 staining. In the control group, the nuclei of the HepG 2 cells were round and homogeneously stained (Fig. 2A). However, pitavastatin treated HepG 2 cells showed granular apoptotic bodies (Fig. 2B), which were clearly related to the HMG-CoA reductase activity due to the addition of Mevalonic acid (MEV) which could recover the morphologic changes of the nucleus (Fig. 2C). These results demonstrate that pitavastatin induces apoptosis of HepG 2 cells.

Downregulation of survivin mRNA expression by pitavastatin in HepG 2 cells. Survivin, a member of the IAP family, is a bifunctional protein that suppresses apoptosis and regulates cell division (4). Forty-eight hours after the treatment with reagents, the expression of survivin mRNA was detected by RT-PCR. The statistical analysis showed that the expression of survivin mRNA in HepG 2 cells was downregulated significantly by pitavastatin at $10 \mu \mathrm{M}$ compared with the control $(\mathrm{p}<0.01)$ (Fig. 4) and MEV abolished the pitavastatin-reduced expression of survivin mRNA.

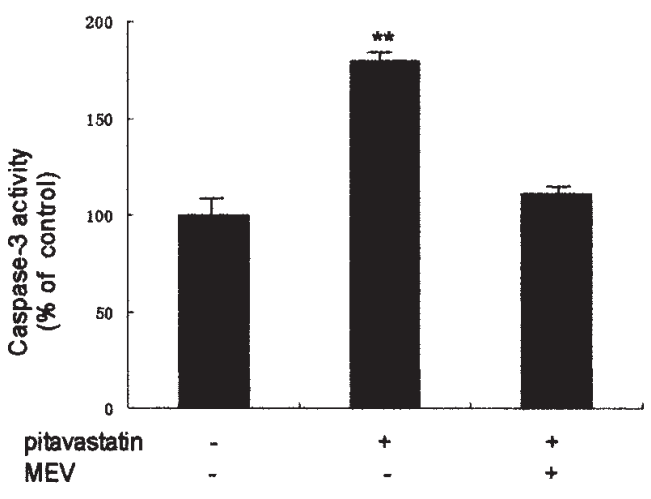

Figure 5. Pitavastatin-induced activity of caspase-3. Subconfluent monolayers of HepG 2 cells were exposed to pitavastatin $(10 \mu \mathrm{M})$ alone, or pitavastatin $(10 \mu \mathrm{M})$ and MEV $(1 \mathrm{mM})$ for $48 \mathrm{~h}$. The caspase- 3 activity was measured with a colorimetric protease assay. The results are expressed as percentages of caspase- 3 activity relative to untreated control cells. The data represent means $\pm \mathrm{SD}(\mathrm{n}=3) ;{ }^{* *} \mathrm{p}<0.01$ vs. control.

Induction of capase-3 activity by pitavastatin in HepG 2 cells. Caspases, the cytoplasmic aspartate-specific cysteine proteases, have been shown to play a central role in the apoptotic signaling pathway. Caspase-3, a member of the caspase family, was shown to play an essential role in apoptosis induced by a variety of stimuli (13-15). Finally, we examined whether caspase- 3 activity was increased during pitavastatin-induced apoptosis in HepG 2 cells. Fig. 5 shows the appearance of the caspase- 3 activity following exposure to $10 \mu \mathrm{M}$ pitavastatin for $48 \mathrm{~h}$, thus indicating that pitavastatin efficiently activated caspase- 3 in HepG 2 cells. As expected, $\mathrm{MEV}$ also suppressed the pitavastatin-induced caspase- 3 activity.

\section{Discussion}

It has recently been suggested that extra hepatic effects of statins might play a potentially beneficial role in cancer therapy. The presumption is based on experimental data obtained both in vitro and in vivo $(16,17)$. Simvastatin (1-30 $\mu \mathrm{M})$ was demonstrated to have a cancer preventing ability (18). Fluvastatin inhibited the proliferation of Huh 7 cells by inducing apoptosis and G1/S cell cycle arrest. A maximal decrease in cell number by $90 \%$ was observed at $50 \mu \mathrm{M}$ and the $\mathrm{IC}_{50}$ of fluvastatin was $10 \pm 3 \mu \mathrm{M}$ in Huh 7 cells (9). Gel shift 
assay revealed that cerivastatin at $25 \mathrm{ng} / \mathrm{ml}$ displayed a potent anti-invasive effect on human breast cancer cells (MDA-MB231 cells), which could be related to NF- $\mathrm{KB}$ inhibition (19). Statin in vitro models have been shown to interact with and increase the efficiency of chemotherapeutic agents, such as 5-fluorouracil, cisplation or doxorubicin (20).

Due to metabolic and morphological similarities, monocytic HepG 2 cells have been accepted as a good model of hepatocellular carcinoma. Pitavastatin, also known as NK-104, is a novel highly potent inhibitor of HMG-CoA reductase, the ratelimiting enzyme in cholesterol biosynthesis (10). In the present study, pitavastatin significantly suppressed the proliferation of HepG 2 cells. Moreover, the nuclear morphology and apoptosis rate analyzed quantitatively by flow cytometry suggested that an apoptotic cell death mechanism was also potentially involved in this direct cytotoxicity (Figs. 2 and 3).

Tumor development and progression as well as resistance to most oncologic therapies result mainly from a lacking response to apoptotic stimuli (21). Survivin, a member of the IAP family, is a bifunctional protein that suppresses apoptosis and regulates cell division. Previous studies showed that there is a close relationship between survivin and malignant tumors. The expression of survivin is highly cancer-specific and is one of the top four transcripts uniformly upregulated in human cancers, but not in normal tissues (22). The overexpression of survivin appears to correlate with aggressive tumor behavior and poor prognosis in non-small cell lung cancers (23), neuroblastomas (24) and hepatocellular carcinoma (25). Additionally, survivin overexpression is also correlated with insensitivity to chemotherapy and radiotherapy in cancers (26). Inhibiting the expression of survivin can induce tumor cell apoptosis, sensitize tumor cells to chemotherapy and radiotherapy and inhibit tumor-angiogenesis $(27,28)$. Survivin has become an ideal target for the diagnosis and treatment of cancer. To determine whether the apoptosis of HepG 2 cells by pitavastatin was mediated by a decrease in survivin mRNA expression, HepG 2 cells were treated with pitavastatin $(10 \mu \mathrm{M})$ for $48 \mathrm{~h}$, as shown in Fig. 4. RT-PCR analysis revealed that pitavastatin suppressed survivin mRNA expression levels compared with the control. This finding demonstrates that the apoptosis of HepG 2 cells by pitavastatin is associated with the downregulation of survivin mRNA expression.

In addition, the mechanisms by which survivin inhibits cell apoptosis and cell division are still highly controversial (29). Survivin may regulate apoptosis by directly inhibiting the activity of caspases and by mainly suppressing the activity of caspase-3 and caspase-7 (30). Disruption of survivinmicrotubule interactions could result in the loss of survivin's anti-apoptosis function and increase caspase- 3 activity, a mechanism involved in cell death during mitosis (31). Caspase- 3 is the ultimate executioner caspase that is essential for the nuclear changes associated with apoptosis (32). In the present study, we found that the pitavastatin-induced apoptosis of HepG 2 was also related to the increase in caspase- 3 activity (Fig. 5).

In summary, we have shown that pitavastatin, which is a well-characterized and well-established pharmaceutical, induces apoptosis of HepG 2 cells through nuclear degradation, suppressing the survivin mRNA and increasing caspase- 3 activity. The significance of these findings for the anti-cancer effects of pitavastatin should be characterized in more detail.

\section{Acknowledgements}

This study was supported by the Shanghai Leading Academic Discipline Project (no. Y0302).

\section{References}

1. Huether A, Hopfner M, Baradari V, Schuppan D and Scherubl H: EGFR blockade by cetuximab alone or as combination therapy for growth control of hepatocellular cancer. Biochem Pharmacol 70: 1568-1578, 2005.

2. Goldstein JL and Brown MS: Regulation of mevalonate pathway. Nature 343: 425-430, 1990.

3. Chan KK, Oza AM and Siu LL: The statins as anti-cancer agents. Clin Cancer Res 9: 10-19, 2003.

4. Wall NR, O'Connor DS, Plescia J, Pommier Y and Altieri DC: Suppression of survivin phosphorylation on Thr34 by flavopiridol enhances tumor cell apoptosis. Cancer Res 63: 230-235, 2003.

5. Grossman D, McNiff JM, Li F, et al: Expression of the apoptosis inhibitor, Survivin, in nonmelanoma skin cancer and gene targeting in a keratinocyte cell line. Lab Invest 79: 1121-1126, 1999.

6. Fernandes-Alnemri T, Litwack G and Alnemri ES: CPP32, a novel human apoptotic protein with homology to Caenorhabditis elegans cell death protein Ced-3 and mammalian interleukin-1 beta-converting enzyme. J Biol Chem 269: 30761-30764, 1994.

7. Tormanen-Napankangas U, Soini Y, Kahlos K, Kinnula V and Paakko P: Expression of caspases-3, -6 and -8 and their relation to apoptosis in non-small cell lung carcinoma. Int J Cancer 93: 192-198, 2001.

8. Kania J, Konturek SJ, Marlicz K, Hahn EG and Konturek PC: Expression of survivin and caspase-3 in gastric cancer. Dig Dis Sci 48: 266-271, 2003.

9. Sutter AP, Maaser K, Hopfner M, Huether A, Schuppan D and Scherubl H: Cell cycle arrest and apoptosis induction in hepatocellular carcinoma cells by HMG-CoA reductase inhibitors. Synergistic anti-proliferative action with ligands of the peripheral benzodiazepine receptor. J Hepatol 43: 808-816, 2005.

10. Kajinami K, Takekoshi N and Saito Y: Pitavastatin: efficacy and safety profiles of a novel synthetic HMG-CoA reductase inhibitor. Cardiovasc Drug Rev 21: 199-215, 2003.

11. Zhao FL, Hu JH and Zhu XZ: Monocyte-mediated rotenone neurotoxicity towards human neuroblastoma SH-SY5Y: Role of mitogen-activated protein kinases. Biol Pharm Bull 29: 1372-1377, 2006.

12. Sarela AI, Macadam RCA, Farmery SM, Markham AF and Guilou PJ: Expression of the anti-apoptosis gene, Survivin, predicts death from recurrent colorectal carcinoma. Gut 46: 645-650, 2000.

13. Devarajan E, Sahin AA, Chen JS, Krishnamurthy RR, Aggarwal N, Brun AM, Sapino A, Zhang F, Sharma D, Yang XH, Tora AD and Mehta K: Downregulation of caspase-3 in breast cancer: a possible mechanism for chemoresistance. Oncogene 21: 8843-8851, 2002.

14. Chen T, Yang I, Irby R, Shain KH, Wang HG, Quackenbush J, Coppola D, Cheng JQ and Yeatman TJ: Regulation of caspaseexpression and apoptosis by adenomatous polyposis coli. Cancer Res 63: 4368-4374, 2003.

15. Ceruti S, Beltrami E, Matarrese P, Mazzola A, Cattabeni F, Malorni W and Abbracchio MP: A key role for caspase-2 and caspase- 3 in the apoptosis induced by 2-chloro-2-deoxyadenosine (cladribine) and 2-chloro-adenosine in human astrocytoma cells. Mol Pharmacol 63: 1437-1447, 2003.

16. Jakobisiak M and Golab J: Potential anti-tumor effects of statins (Review). Int J Oncol 23: 1055-1069, 2003.

17. Graaf MR, Richel DJ, van Noorden CJ and Guchelaar HJ: Effects of statins and farnesyl transferase inhibitors on the development and progression of cancer. Cancer Treat Rev 30: 609-641, 2004

18. Otsuki T, Sakaguchi H, Hatayama T, et al: Effects of an HMGCoA reductase inhibitor, simvastatin, on human myeloma cells. Oncol Rep 11: 1053-1058, 2004.

19. Denoyelle C, Vasse M, Korner M, Mishal Z, Ganne F and Vannier JP: Cerivastatin, an inhibitor of HMG-CoA reductase, inhibits the signaling pathways involved in the invasiveness and metastatic properties of highly invasive breast cancer cell lines: an in vitro study. Carcinogenesis 22: 1139-1148, 2001. 
20. Fritz G, Brachetti C and Kaina B: Lovastatin causes sensitization of HeLa cells to ionizing radiation-induced apoptosis by the abrogation of G2 blockage. Int J Radiat Biol 79: 601-610, 2003.

21. Westphal S and Kalthoff H: Apoptosis: targets in pancreatic cancer. Mol Cancer 2: 6, 2003.

22. Velculescu VE, Madden SL, Zhang L, et al: Analysis of human transcriptomes. Nat Genet 23: 387-388, 1999.

23. Shinohara ET, Gonzalez A, Massion PP, et al: Nuclear survivin predicts recurrence and poor survival in patients with resected non small cell lung carcinoma. Cancer 103: 1685-1692, 2005.

24. Ito R, Asami S, Motohashi S, et al: Significance of survivin mRNA expression in prognosis of neuroblastoma. Biol Pharm Bull 28: 565-568, 2005.

25. Bao ST, Gui SQ and Lin MS: Relationship between expression of Smac and Survivin and apoptosis of primary hepatocellular carcinoma. Hepatobiliary Pancreat Dis Int 5: 580-583, 2006.

26. Rodel C, Haas J, Groth A, Grabenbauer GG, Sauer R and Rodel F: Spontaneous and radiation-induced apoptosis in colorectal carcinoma cells with different intrinsic radiosensitivities: survivin as a radioresistance factor. Int J Radiat Oncol Biol Phys 55: 1341-1347, 2003.
27. Lu B, Mu Y, Cao C, et al: Survivin as a therapeutic target for radiation sensitization in lung cancer. Cancer Res 64: 2840-2845, 2004.

28. Coma S, Noe V, Lavarino C, et al: Use of siRNAs and antisense oligonucleotides against survivin RNA to inhibit steps leading to tumor angiogenesis. Oligonucleotides 14: 100-113, 2004.

29. Chiou SK, Jones MK and Tarnawski AS: Survivin - an antiapoptosis protein: its biological roles and implications for cancer and beyond. Med Sci Monit 9: PI25-P129, 2003.

30. Shin S, Sung BJ, Cho YS, et al: An anti-apoptotic protein human survivin is a direct inhibitor of caspases-3 and -7. Biochemistry 40: 1117-1123, 2001.

31. Li F, Ambrosini G, Chu EY, Plescia J, Tognin S, Marchisio PC and Altieri DC: Control of apoptosis and mitotic spindle checkpoint by survivin. Nature 396: 580-584, 1998.

32. Chen YC, Shen SC, Lee WR, et al: Emodin induces apoptosis in human promyeloleukemic HL-60 cells accompanied by activation of caspase- 3 cascade but independent of reactive oxygen species production. Biochem Pharmacol 64: 1713-1724, 2002 . 